\title{
MicroRNA-107 prevents amyloid- $\beta$-induced neurotoxicity and memory impairment in mice
}

\author{
BOHUI SHU, XIAOYAN ZHANG, GANQIN DU, QIZHI FU and LINA HUANG \\ The First Affiliated Hospital and College of Clinical Medicine of Henan University of Science and Technology, \\ Luoyang, Henan 471003, P.R. China
}

Received June 8, 2017; Accepted December 15, 2017

DOI: $10.3892 /$ ijmm.2017.3339

\begin{abstract}
The pathogenesis of Alzheimer's disease (AD) has still not been fully elucidated, however it is thought that the build up of amyloid plaque at least partially causes the symptoms of AD. MicroRNAs (miRNAs) are endogenous non-coding small RNA molecules that regulate the expression and degradation of proteins. The present study induced symptoms of $\mathrm{AD}$ in mice via intraventricular injection of amyloid- $\beta$ 1-42 (A $\beta 1-42)$, which decreased levels of miR-107. However, miR-107 levels increased following administration of miR-107 mimic, a double-stranded RNA molecule designed to imitate the native miRNA. Intraventricular injection of A $\beta 1-42$ aggregates led to spatial memory impairments, inhibited hippocampal long-term potentiation (LTP) and resulted in the loss of pyramidal cells in the CA1 region of the hippocampus. The miR-107 mimic reversed the impairments of spatial memory and LTP and the loss of pyramidal neurons caused by $A \beta$ neurotoxicity. Furthermore, the miR-107 mimic reversed the A $\beta$-induced increase in $A \beta 1-42$ and phosphorylated Tau levels. Critically, A $\beta 1-42$ injection decreased levels of brain-derived neurotrophic factor and reduced the phosphorylation of tyrosine receptor kinase $B$ and protein kinase $\mathrm{B}$; these changes were reversed following treatment with the miR-107 mimic. Collectively, these results demonstrated that miR-107 may be a potential target for the treatment of AD.
\end{abstract}

\section{Introduction}

Alzheimer's disease (AD) is a progressive disorder of the brain and nervous system thought to be caused by the buildup of amyloid plaques and loss of pyramidal neurons in the brain (1). AD disrupts the electrical signals between

Correspondence to: Dr Lina Huang, The First Affiliated Hospital and College of Clinical Medicine of Henan University of Science and Technology, 24 Jinghua Road, Luoyang, Henan 471003, P.R. China E-mail: lina_huang1@sina.com

Key words: microRNA-107, Alzheimer's disease, amyloid- $\beta$, memory neurons that are responsible for the formation of thoughts and memories (2). It is considered that the formation of plaques, caused by extracellular deposits of amyloid $\beta(A \beta)$, is responsible for the pathology of AD (3). Therefore, early removal of plaque in the brain may be critical to facilitate the effective treatment of AD. Genetic models of AD, particularly amyloid precursor protein/presenilin 1 (APP/PS) mice, have been widely used to elucidate the pathogenesis of AD and develop appropriate treatments $(4,5)$. APP/PS mice exhibit typical AD phenotypes, including the impairment of memory and hippocampal long-term potentiation (LTP), loss of pyramidal cells and accumulation of $\mathrm{A} \beta$; however, these symptoms usually appear in mice at a late stage ( $>6$ months of age) (4). $A \beta$ injections induce neurotoxicity and this may be a novel method of inducing $\mathrm{AD}$ in mice, enabling further research to be performed; cell death in mice with a typical AD phenotype has been observed in a short period of time following injection of $\mathrm{A} \beta(6,7)$.

MicroRNAs (miRNAs) are endogenous non-coding small RNA molecules that are 21-25 nucleotides long, and regulate the degradation and translation of target proteins (8). The function of miRNAs has been well documented in the development and treatment of various types of cancer (9-11). miRNAs serve critical roles in neurodegeneration and neuroprotection $(12,13)$ and it has been reported that miRNAs regulate spinogenesis in the central nervous system (14). Furthermore, previous studies have suggested that miRNAs are involved in the pathogenesis of $\operatorname{AD}(15,16)$.

It has been demonstrated that miR-107 expression is downregulated in the temporal cortical grey matter during the early phases of AD (17,18). Furthermore, accumulation of $A \beta$ in the brain serves an important role in the pathogenesis of AD (6). It has been reported that miRNAs regulate multiple aspects of AD development and progression, indicating that targeting miRNAs may be a novel strategy of treating $\operatorname{AD}(15,16)$. Furthermore, it has been demonstrated that osthole decreases $A \beta$ levels in $A D$ by upregulating miR-107 (19). However, it remains unknown whether miR-107 is critical in the synthesis of plaques and whether it serves a specific role in AD. The present study used an A $\beta 1$-42-induced neurotoxicity rat model to investigate the function of miR-107 in AD and elucidate the potential mechanisms involved. The results indicate that miR-107 may be a potential method of treating AD. 


\section{Materials and methods}

Animals and $A D$ modeling. A total of 60 male C57 mice (6 months old, weighing 25-30 g) were purchased from the Shanghai Laboratory Animal Center (Shanghai, China). Mice were housed in a room maintained at a temperature of $23 \pm 2^{\circ} \mathrm{C}$, a relative humidity of $45-65 \%$ and experienced a $12 \mathrm{~h}$ light/dark cycle. Animals had ad libitum access to food and water. All experimental procedures were approved by the Ethics Committee of Henan University of Science and Technology (Luoyang, China).

Animals were randomly divided into five groups (each, $n=12$ ): A control group, an $A \beta$ model group, a scramble control (SC) $+\mathrm{A} \beta$ model group, a miR-107 mimic $+\mathrm{A} \beta$ model group and an miR-107 mimic + control group. Single intracerebroventricular (icv) injections of $A \beta$ aggregates were used to induce AD symptoms, as previously described (20). A $\beta 1-42$ (2 $\mu \mathrm{g}$ /mouse; Sigma-Aldrich; Merck KGaA, Darmstadt, Germany) was dissolved and diluted in distilled water, and incubated to induce aggregation at $37^{\circ} \mathrm{C}$ for 4 days. Rats received one injection of aggregated A $\beta 1-42(1 \mu \mathrm{l})$ directly into the third ventricle of the mouse brain (specific parameters: Anteroposterior, $-2.5 \mathrm{~mm}$; mediolateral, $0 \mathrm{~mm}$; dorsoventral, $-3.0 \mathrm{~mm}$ relative to bregma). A vehicle (1 $\mu 1$ saline) was injected (icv) as a control.

Treating mice with the miR-107 mimic. miR-107 mimic and SC were provided by Shanghai GenePharma Co., Ltd. (Shanghai, China) and administered to the mice icv 30 min prior to icv injection of $1 \mu \mathrm{l} A \beta 1-42$. A total of 7 days after injection with A $\beta 1-42$, a Morris water maze test was conducted to test spatial memory. A total of 6 mice in each group were then sacrificed to isolate hippocampal slices for electrophysiological experiments. Additional mice underwent Nissl staining, as well as biochemical or molecular experiments.

Morris water maze. A total of 7 days after A $\beta 1-42$ injections, the spatial learning and memory ability of mice was assessed using a Morris water maze test (Panlab, Barcelona, Spain). A training protocol lasting for 5 consecutive days was used that involved conducting 4 trials/day in a water maze. The maximum time allowed for each mouse to find the platform was $90 \mathrm{sec}$. Each trial had a different starting point and if mice failed to find the platform in $90 \mathrm{sec}$, they would be guided to the platform manually and kept at the platform for $10 \mathrm{sec}$. The time spent by each mouse to reach the platform, known as the escape latency period, was counted as $90 \mathrm{sec}$.

The spatial probe test was conducted on day 6 and lasted for $90 \mathrm{sec}$. The platform was removed and each mouse was released opposite the target quadrant, facing the wall of the pool. In the probe test, the time that mice spent in the target quadrant was recorded to assess their spatial memory.

Electrophysiological experiments. Mice were anesthetized with isoflurane (1\% in oxygen) via inhalation. Following anesthesia, mice used in electrophysiological experiments were decapitated, brains were quickly isolated and placed on ice. Subsequently, brains were immersed in pre-cooled cutting solution (124 NaCl, $26 \mathrm{NaHCO}_{3}, 10 \mathrm{D}$-glucose, $3 \mathrm{KCl}$, $1.25 \mathrm{KH}_{2} \mathrm{PO}_{4}, 5 \mathrm{MgSO}_{4}$ and $3.4 \mathrm{CaCl}_{2}$ ) and hippocampal slices
(400 $\mu \mathrm{m}$ ) were prepared in cutting solution, as previously described (21). Slices were transferred to an interface recording chamber consisting of a warm, humidified atmosphere of $95 \%$ $\mathrm{O}_{2} / 5 \% \mathrm{CO}_{2}$ and were continuously perfused with oxygenated and preheated $\left(32 \pm 0.5^{\circ} \mathrm{C}\right)$ artificial cerebrospinal fluid (aCSF; $110 \mathrm{mM} \mathrm{NaCl}, 5 \mathrm{mM} \mathrm{KCl}, 2.5 \mathrm{mM} \mathrm{CaCl}_{2}, 1.5 \mathrm{mM} \mathrm{MgSO}_{4}$, $1.24 \mathrm{mM} \mathrm{KH}_{2} \mathrm{PO}_{4}, 10 \mathrm{mM}$ D-glucose, $27.4 \mathrm{mM} \mathrm{NaHCO}_{3}$ ) at a speed of $1.5 \mathrm{ml} / \mathrm{min}$. The field excitatory postsynaptic potential was elicited by stimulating the Schaffer collateral pathway with twisted nichrome wires. The input-output and LTP induced by $\theta$-burst stimulation (TBS; 10 bursts of 4 pulses at $100 \mathrm{~Hz}$ delivered at 5-Hz intervals) were measured.

ELISA. Hippocampal A $\beta 1-42$ was measured using ELISA. Hippocampi from different groups were homogenized in homogenization buffer ( $5 \mathrm{M}$ guanidine $\mathrm{HCl} / 50 \mathrm{mM}$ Tris- $\mathrm{HCl})$ and centrifuged at $11,587 \mathrm{xg}$ for $10 \mathrm{~min}$ at $4^{\circ} \mathrm{C}$. Protein concentrations were determined using a bicinchoninic acid (BCA) assay kit (Thermo Fisher Scientific, Inc., Waltham, MA, USA). Supernatant fractions were analyzed using an A $31-42$ ELISA kit (cat. no. KHB3441; Invitrogen; Thermo Fisher Scientific, Inc.) following the manufacturer's protocol. Absorbance was measured at $450 \mathrm{~nm}$ using a microplate reader.

Reverse transcription-quantitative polymerase chain reaction $(R T-q P C R)$. Total RNA was extracted from the hippocampus using TRIzol reagent (Invitrogen; Thermo Fisher Scientific, Inc.). RT was then performed using the Moloney murine leukemia virus reverse transcriptase (cat. no. M1705; Promega, Madison, WI, USA) and dNTPs (Thermo Fisher Scientific, Inc.) in First-Strand Buffer (cat. no. M1705; Promega) for $50 \mathrm{~min}$ at $37^{\circ} \mathrm{C}$ following the manufacturer's protocol. qPCR was performed to quantify miR-107 expression in the hippocampus using the mmu-mir-107 RT-PCR Detection and U6 Calibration kit (cat. no. abx096666; Abbexa Ltd., Cambridge, UK) on a quantitative thermal cycler (Mastercycler ${ }^{\circledR}$ ep realplex; Eppendorf, Hamburg, Germany). The thermocycling conditions were as follows: $95^{\circ} \mathrm{C}$ denaturation for $45 \mathrm{sec}, 58^{\circ} \mathrm{C}$ annealing for $60 \mathrm{sec}$ and $72^{\circ} \mathrm{C}$ extension $60 \mathrm{sec}$ for 35 cycles. The following primers were used in qPCR (5'-3'): miR-107 forward, 5'-GCCAAGCCCACTCAGCTGCCAGCC'-3 and reverse, 5'-GGCTGGCAGCTGAGTGGGCTTGGC-3'; U6, forward, 5'-CTCGCTTCGGCAGCACA-3' and reverse, 5'-AACGCTTCACGAATTTGCGT-3'. The relative expression of mature miR-107 was calculated against U6 RNA (the internal control) using the $2^{\Delta \triangle C q}$ method (22).

Western blotting. Hippocampi homogenates were obtained and lysed using radioimmunoprecipitation assay lysis buffer (Thermo Fisher Scientific, Inc.). Protein concentrations were measured using the BCA protein assay kit (Thermo Fisher Scientific, Inc.). Equivalent amounts of proteins $(25 \mu \mathrm{g} / \mathrm{lane})$ were underwent SDS-PAGE (12\% gel) and transferred onto nitrocellulose membranes. Membranes were blocked in 5\% skim milk for $2 \mathrm{~h}$ at room temperature and incubated with primary antibodies at $4^{\circ} \mathrm{C}$ overnight. The primary antibodies used were for brain-derived neurotrophic factor (BDNF; dilution 1:1,000, cat. no. AB1534; EMD Millipore, Billerica, MA, USA), phosphorylated (p)-Tau (dilution 1:3,000, cat.no. 12885,), Tau (dilution 1:3,000, cat. no. 4019p-tropomyosin receptor 
kinase (TrkB; dilution 1:3,000, cat. no. 4619), TrkB (dilution 1:3,000, cat. no. 4607), p-AKT (dilution 1:3,000, cat. no. 4060), AKT (dilution 1:3,000, cat. no. 2920) (all from CST Biological Reagents, Co., Ltd.) and GAPDH (1:10,000, cat. no. AB2302; EMD Millipore). Following three washes with phosphate-buffered saline (PBS), membranes were labeled with specific horseradish peroxidase (HRP)-coupled secondary antibodies [anti-mouse immunoglobulin (Ig) G HRP or anti-rabbit IgG HRP; cat. no. A16104SAMPLE, Thermo Fisher Scientific, Inc.) for $2 \mathrm{~h}$ at room temperature. Protein bands were visualized by staining with a chemiluminescent substrate detection reagent (Thermo Fisher Scientific, Inc.). Grayscale analysis of target bands was performed using ImageJ software version 7.0 (National Institutes of Health, Bethesda, MD, USA).

Statistical analyses. Data are presented as the mean \pm standard error of the mean. All statistical analyses were performed using GraphPad Prism 6.0 (GraphPad Software, Inc., La Jolla, CA, USA). One-way analysis of variance followed by Bonferroni correction was performed to compare differences between groups. $\mathrm{P}<0.05$ was considered to indicate a statistically significant difference.

\section{Results}

miR-107 mimic prevents the A $\beta$-induced reduction of $m i R-107$ in the hippocampus. miR-107 expression in the hippocampus was measured 7 days following AD induction or miR-107 treatment. Following $A \beta$ injection, miR-107 levels were significantly decreased compared with the control $(\mathrm{P}<0.05)$ (Fig. 1). The miR-107 mimic significantly prevented the reduction of miR-107 compared with the $A \beta$ group $(\mathrm{P}<0.05)$; however, the scramble control did not affect miR-107 levels. Additionally, application of the miR-107 mimic in control mice did not affect miR-107 expression.

miR-107 mimic prevents A 3 -induced cell death in the CAI region. Cell loss is a major pathological characteristic of the AD phenotype; therefore the present study speculated whether miR-107 would prevent cell loss in the A $\beta$ model. Nissl staining was used to measure cell numbers in the CA1 region 7 days following AD induction or miR-107 treatment (Fig. 2A). Significant cell loss was observed in the CA1 region of $\mathrm{A} \beta$-injected mice compared with control mice $(\mathrm{P}<0.05)$ (Fig. 2B and C). However, application of the miR-107 mimic significantly prevented the cell loss induced by $\mathrm{A} \beta$ $(\mathrm{P}<0.05)$. The SC did not prevent the cell loss induced by $\mathrm{A} \beta$. Furthermore, the administration of miR-107 to normal mice did not affect cell numbers.

miR-107 mimic prevents the A $\beta$-induced impairment of basal synaptic transmission and LTP. Electrophysiological experiments were used to detect synaptic transmission and LTP in Schaffer collateral-CA1 synapses 7 days following AD induction or miR-107 treatment. The input-output of synaptic transmission was significantly reduced when delivering a 40 - and $50-\mu \mathrm{A}$ stimulus in the $\mathrm{A} \beta$ group compared with the control $(\mathrm{P}<0.05)$ (Fig. 3A). Furthermore, application of the miR-107 mimic but not SC significantly prevented the impairment of input-output compared with the $A \beta$ group

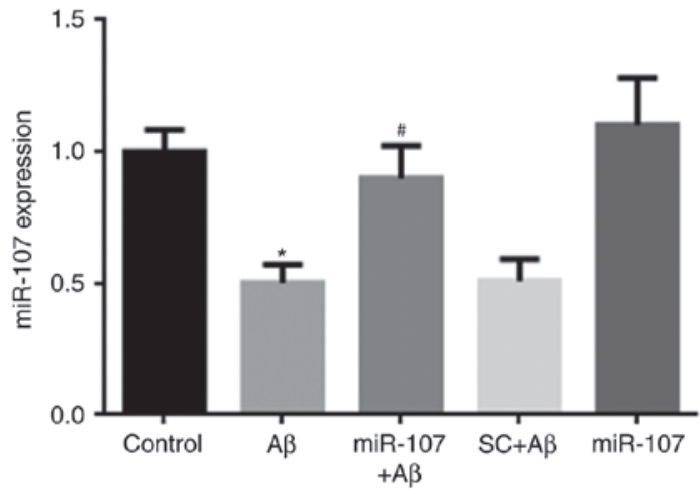

Figure 1. miR-107 mimic prevents the $\mathrm{A} \beta$-induced reduction of miR-107 in the hippocampus. Data are presented as mean \pm standard error of the mean, as determined by one-way analysis of variance. $n=12$. ${ }^{*} \mathrm{P}<0.05$ vs. control; ${ }^{\#} \mathrm{P}<0.05$ vs. SC+A $\beta$. SC, scramble control; $\mathrm{A} \beta$, amyloid $\beta$; miR, microRNA.

$(\mathrm{P}<0.05)$. The $\mathrm{SC}$ had no effect on synaptic transmission following AD induction. LTP was induced in the hippocampi of control mice but was significantly impaired in $A \beta$ model mice $(\mathrm{P}<0.050$ (Fig. 3B). However, the miR-107 mimic significantly reversed LTP impairment $(\mathrm{P}<0.05)$. SC had no effect on the LTP compared with the A $\beta$ group. Quantification of the LTP data at $1 \mathrm{~h}$ demonstrated that LTP was significantly reduced in the $\mathrm{A} \beta$ group compared with the control $(\mathrm{P}<0.05)$ (Fig. $3 \mathrm{C})$. This reduction was reversed by the miR-107 mimic $(\mathrm{P}<0.05)$, but not by the SC. The application of miR-107 in normal controls did not affect the LTP.

miR-107 mimic prevents the A $\beta$-induced impairment of spatial memory. Spatial memory was examined using the Morris water maze 7 days following AD induction or miR-107 treatment. Mice that were administered $\mathrm{A} \beta$ exhibited reduced learning during the training period (Fig. 4A), although this reduction was not significant. During the test period, the time spent in the platform quadrant by the $A \beta$ group was significantly lower than that of the control group $(\mathrm{P}<0.05)$. However, miR-107 prevented memory impairment in A $\beta$-injected mice $(\mathrm{P}<0.05)$ (Fig. 4B) although it did not promote memory in control mice.

miR-107 mimic prevents the A $\beta$-induced increase of A $1-42$ and $p$-Tau. AD proteins were also detected 7 days following AD induction or miR-107 treatment. Levels of endogenous A $\beta$ 1-42 were significantly increased in $A \beta$-injected mice compared with controls $(\mathrm{P}<0.05)$ (Fig. 5A). miR-107 significantly reduced the levels of $A \beta 1-42$ in $A \beta$-injected mice $(\mathrm{P}<0.05)$ but not in normal mice. The level of Tau phosphorylation was also measured. $A \beta$ significantly increased $\mathrm{p}$-Tau levels compared with the control $(\mathrm{P}<0.05)$ (Fig. 5B), however, this was reversed following the administration of miR-107 $(\mathrm{P}<0.05)$. miR-107 administration did not affect Tau phosphorylation in healthy control mice.

miR-107 mimic prevents the A $\beta$-induced depression of the $B D N F-T r k B$ and AKT pathways. The mechanisms involved behind the effects of miR-107 in the A $\beta$ model of AD were determined. The expression of $\mathrm{p}-\mathrm{AKT}, \mathrm{p}$-TrkB and BDNF were measured and quantified. Levels of mature BDNF were 

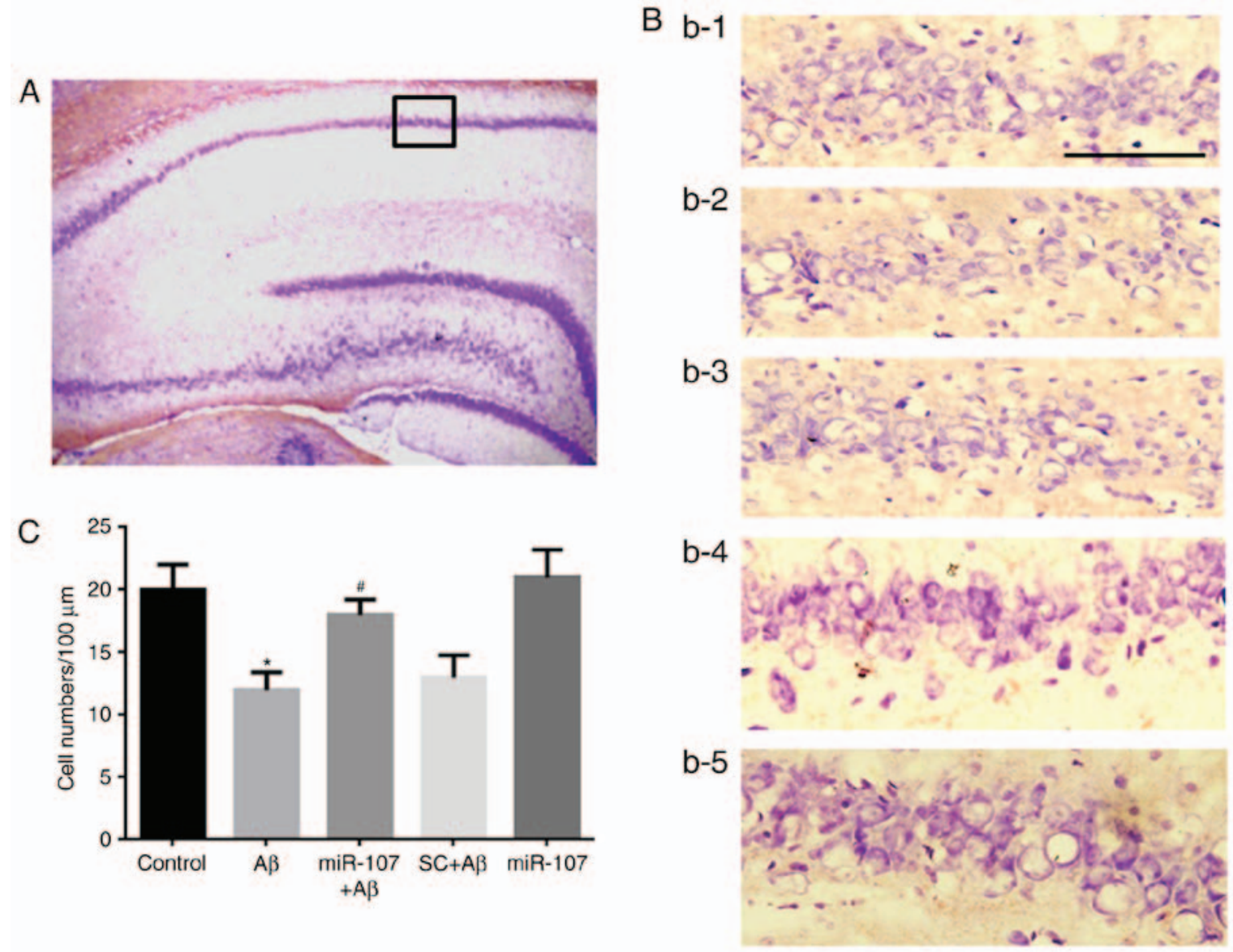

Figure 2. miR-107 mimic prevents A $\beta$-induced cell loss in the CA1 region. (A) Image of hippocampus following Nissl staining (magnification, $x 100)$. The black square indicates the CA1 region, amplified (magnification, $\mathrm{x} 400$ ). (B) Images of the CA1 region. B1, B2, B3, B4 and B5 represent the control, A $\beta$, $\mathrm{SC}+\mathrm{A} \beta, \mathrm{miR}-107+\mathrm{A} \beta$ and miR-107 groups, respectively. Purple staining indicates pyramidal neurons. Scale bar, 100. (C) Quantification of cell numbers in the CA1 region in the different groups. Data are presented as the mean \pm standard error of the mean, as determined by one-way analysis of variance. $\mathrm{n}=12$. ${ }^{*} \mathrm{P}<0.05$ vs. control; ${ }^{\mathrm{P}}<0.05$ vs. $\mathrm{SC}+\mathrm{A} \beta . \mu \mathrm{m}$. SC, scramble control; $\mathrm{A} \beta$, amyloid $\beta ;$ miR, microRNA.

significantly reduced in $\mathrm{A} \beta$-injected mice compared with the control $(\mathrm{P}<0.05)$ (Fig. 6A and $\mathrm{B})$. This reduction was attenuated by the miR-107 mimic $(\mathrm{P}<0.05)$. miR-107 did not affect the expression of mature BDNF in normal control mice. The expression of $\mathrm{p}$-TrkB was also determined in the different groups. $A \beta$ reduced the expression of $p$-TrkB compared with the control $(\mathrm{P}<0.05)$; however, treatment with miR-107 significantly increased TrkB phosphorylation in the $A \beta$ group $(\mathrm{P}<0.05)$ (Fig. 6A and C). Finally, AKT phosphorylation was also quantified. A $\beta$ reduced the expression of $\mathrm{p}$-AKT compared with the control $(\mathrm{P}<0.05)$ (Fig. 6A and $\mathrm{D})$, whereas treatment with miR-107 reversed this reduction $(\mathrm{P}<0.05)$.

\section{Discussion}

The neuroprotective action of miR-107 has been previously reported $(23,24)$; therefore the present study explored the potential function of miR-107 in the treatment of AD. The results demonstrated that miR-107 expression in the hippocampus was downregulated in the $\mathrm{A} \beta$-induced mouse model and that treatment with an miR-107 mimic prevented the reduction of miR-107 expression in the hippocampus induced by $A \beta$ injection. Importantly, the miR-107 mimic prevented A $\beta$-induced behavioral and electrophysiological abnormalities. In addition, it was demonstrated that the miR-107 mimic prevented the production of amyloid plaques and the loss of pyramidal neurons in the CA1 region.

Although the functions of miRNAs have been extensively investigated in cancer $(25,26)$, the potential role of these structures in neurodegenerative diseases has also attracted attention (27). The results of previous studies indicated that miRNAs are involved in a variety of biological processes associated with the onset or treatment of AD (27-29). It has been demonstrated that soluble $A \beta$ (sA $\beta$ ) oligomers contribute to the pathogenesis of $\mathrm{AD}$; the $\mathrm{sA} \beta$-induced expression of miR-134, miR-145 and miR-210 is fully reversed by two selective N-methyl-d-aspartate (NMDA) receptor inhibitors (30). In the same study, insoluble $\mathrm{A} \beta$ fibrils, which constitute the extracellular plaques, did not induce changes in the miRNA profile (30). Prefibrillar sA $\beta$ are more toxic than their insoluble fibrillar counterparts and sA $\beta$ oligomers may represent an early trigger of synaptic damage and cognitive impairment in AD (31). Clinically, it has been reported that miR-107 levels are reduced in the temporal cortical gray matter during the early stages of AD progression (18). Furthermore, the overexpression of miR-107 in the hippocampus exhibits antidepressant-like effects (32). Consistent with the results of a previous study (17), the present study demonstrated that miR-107 expression was reduced in an AD model induced by administration of $\mathrm{A} \beta$. miR-107 mimics not only promoted 

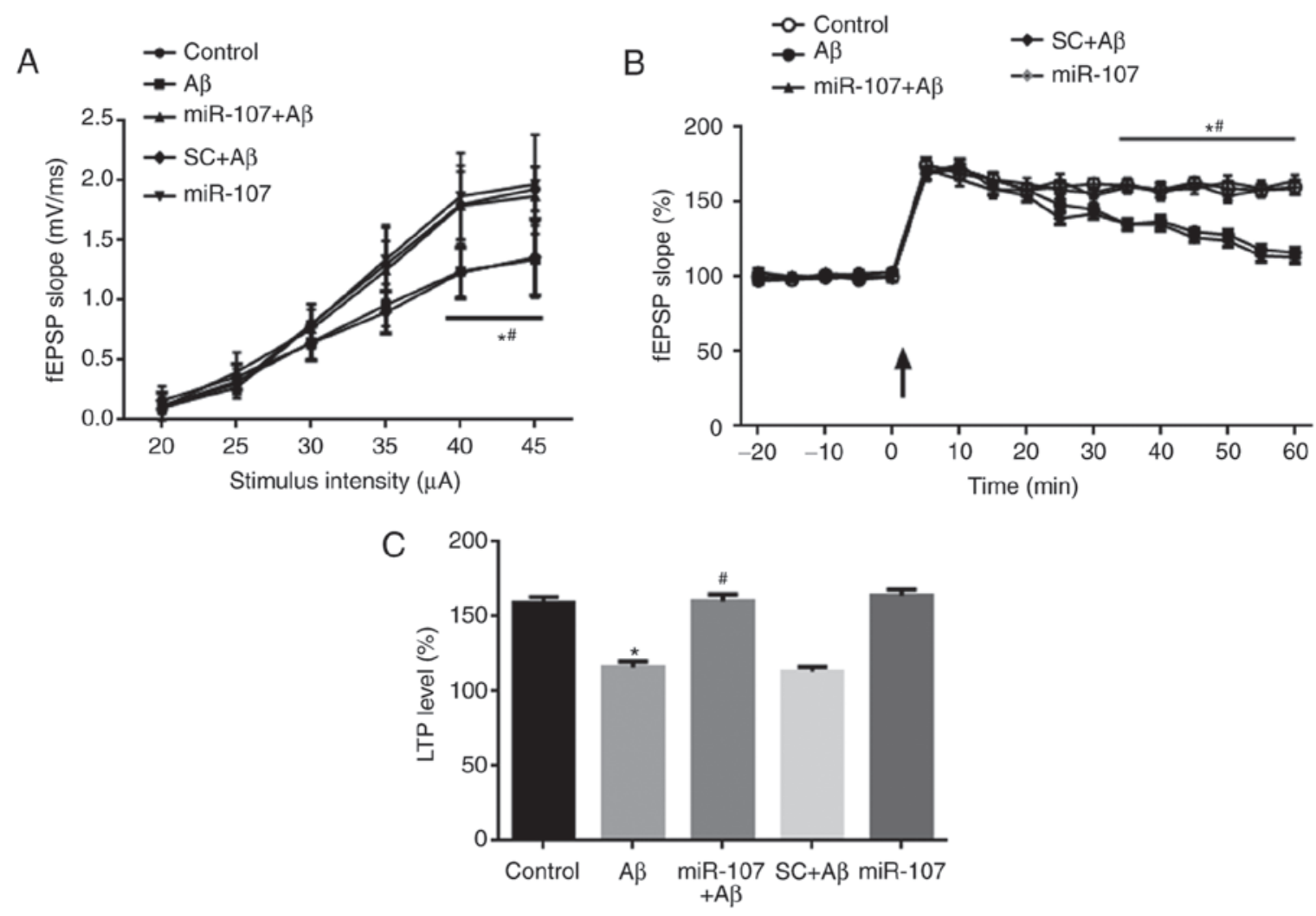

Figure 3. miR-107 mimic prevents the A $\beta$-induced impairment of basal synaptic transmission and LTP. (A) Input-output of basal synaptic transmission. ${ }^{*} \mathrm{P}<0.05$ (A $\beta$ vs. control); ${ }^{*} \mathrm{P}<0.05$ (miR-107+A $\beta$ vs. $\mathrm{SC}+\mathrm{A} \beta$ group); (B) LTP induced by TBS. (arrow indicates initiation of TBS). ${ }^{*} \mathrm{P}<0.05$ (A $\beta$ vs. control); ${ }^{\text {"}} \mathrm{P}<0.05$ (miR-107+A $\beta$ vs. SC+A $\beta$ group); (C) Quantification of LTP $1 \mathrm{~h}$ post-TBS. Data are presented as the mean \pm standard error of the mean, as determined by one-way analysis of variance. $\mathrm{n}=12$. ${ }^{*} \mathrm{P}<0.05$ vs. control; ${ }^{*} \mathrm{P}<0.05$ vs. $\mathrm{SC}+\mathrm{A} \beta$ group. $\mathrm{SC}$, scramble control; $\mathrm{A} \beta$, amyloid $\beta$; LTP, long-term potentiation; miR, microRNA; fEPSP, field excitatory post-synaptic potential; TBS, $\theta$-burst stimulation.
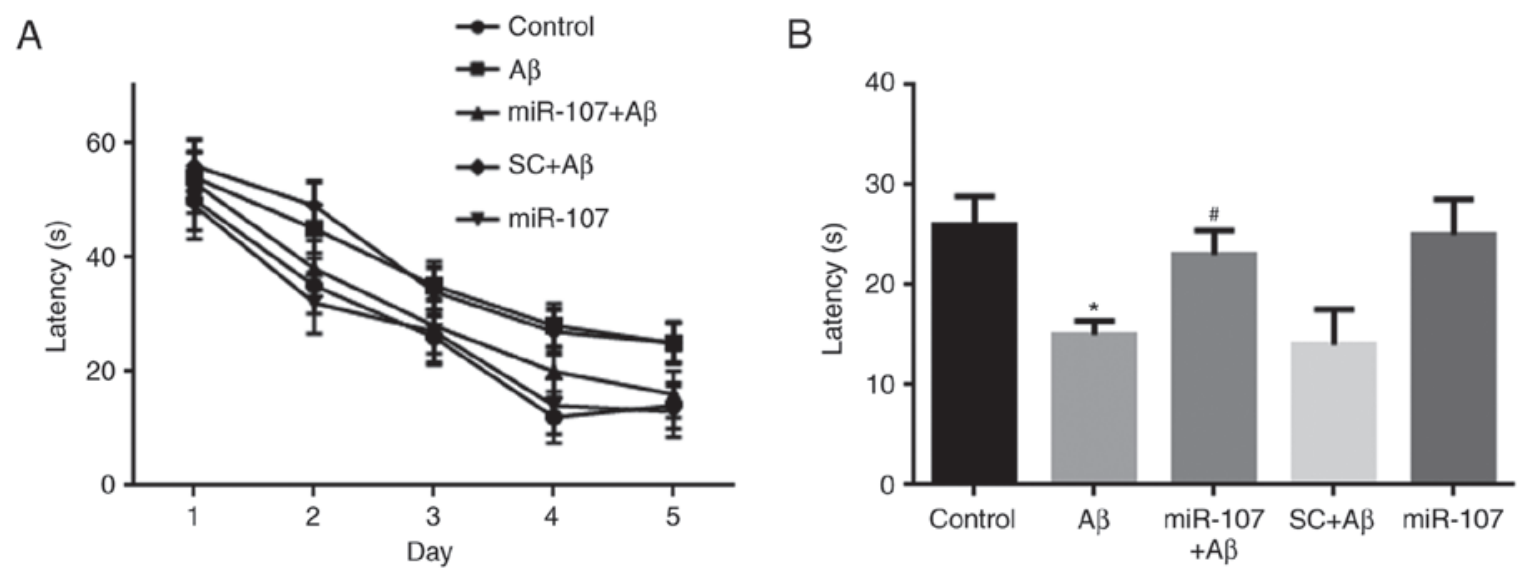

Figure 4. miR-107 mimic prevents the A $\beta$-induced impairment of spatial memory. (A) Latency to find the platform during 5-day training period; (B) Time spent in the platform quadrant following platform removal. Data are presented as the mean \pm standard error of the mean, as determined by one-way analysis of variance. $\mathrm{n}=12$. ${ }^{*} \mathrm{P}<0.05$ vs. control; ${ }^{*} \mathrm{P}<0.05$ vs. $\mathrm{SC}+\mathrm{A} \beta$ group. $\mathrm{SC}$, scramble control; $\mathrm{A} \beta$, amyloid $\beta$; miR, microRNA.

miR-107 expression in the hippocampus, but also reversed the impairment of spatial memory in a model of $A \beta$.

It has been proposed that LTP is the primary cellular model for memory $(33,34)$. The impairment of hippocampal LTP is typical of AD model mice (4). The present study reported that TBS-induced LTP in Schaffer collateral-CA1 synapses was impaired in AD model mice. It was also demonstrated that input-output of the basal synaptic transmission was reduced in an $\mathrm{AD}$ model, consistent with the results of previous studies (4,5). The miR-107 mimic reversed the impairment of basal synaptic transmission. As reported previously, the reduction in excitatory synaptic transmission could also contribute to the LTP impairment observed in AD (35). In addition, inhibition of the BDNF-TrkB pathway, observed following $A \beta$ injection, may account for the impairment of LTP $(36,37)$.

Pyramidal neuron death has also been proposed as a pathological factor underlying the AD phenotype (38-40). The present study determined the number of pyramidal neurons in 


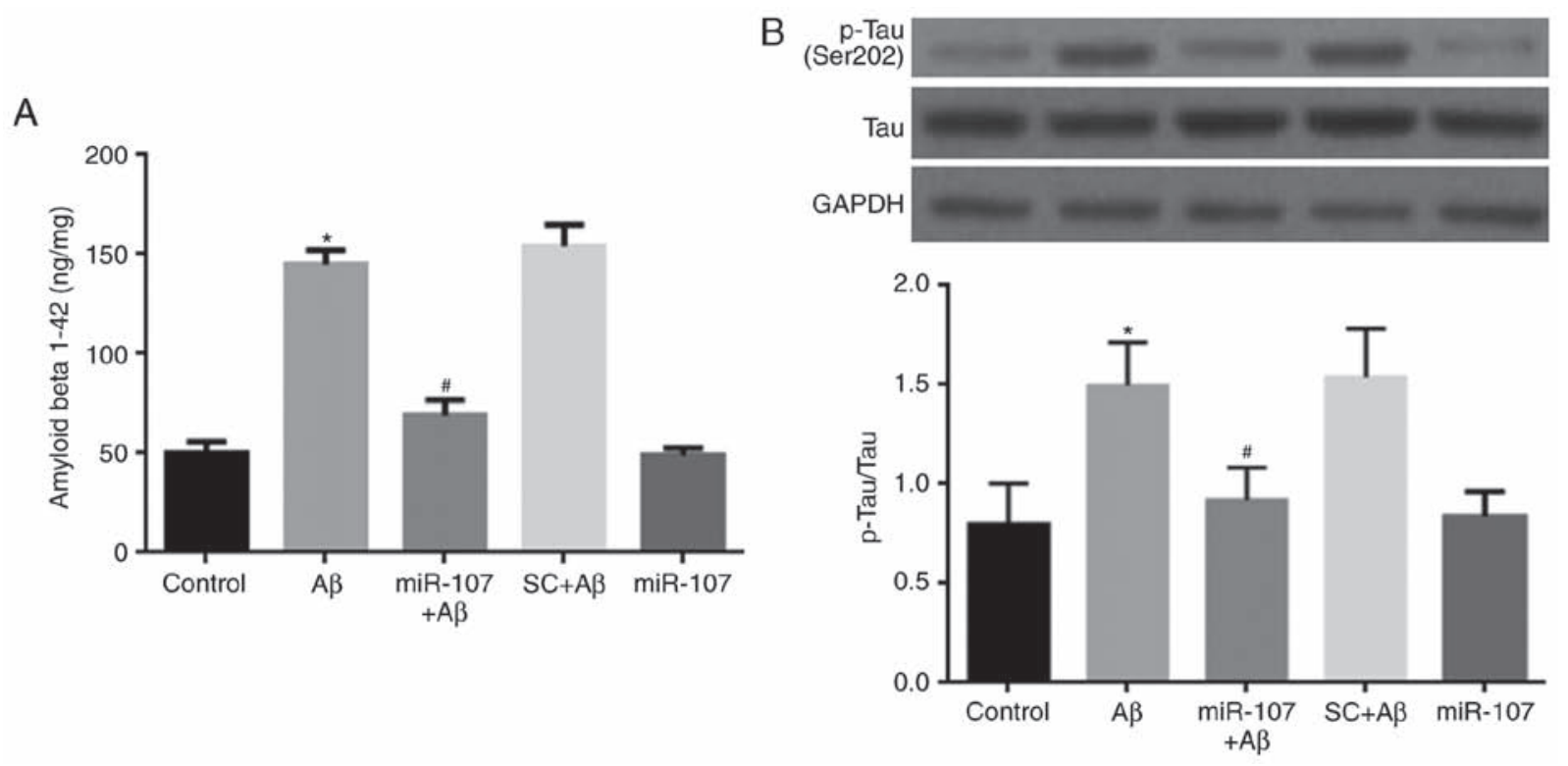

Figure 5. miR-107 mimic prevents the A $\beta$-induced accumulation of A $\beta$ 1-42 and p-Tau. (A) Levels of A $\beta$ 1-42; (B) p-Tau expression. Data are presented as the mean \pm standard error of the mean, as determined by one-way analysis of variance." $\mathrm{P}<0.05$ vs. control; $\mathrm{P}<0.05$ vs. SC+A $\beta$ group. $\mathrm{n}=12$. SC, scramble control; $\mathrm{A} \beta$, amyloid $\beta ; \mathrm{p}-$, phosphorylated; miR, microRNA.
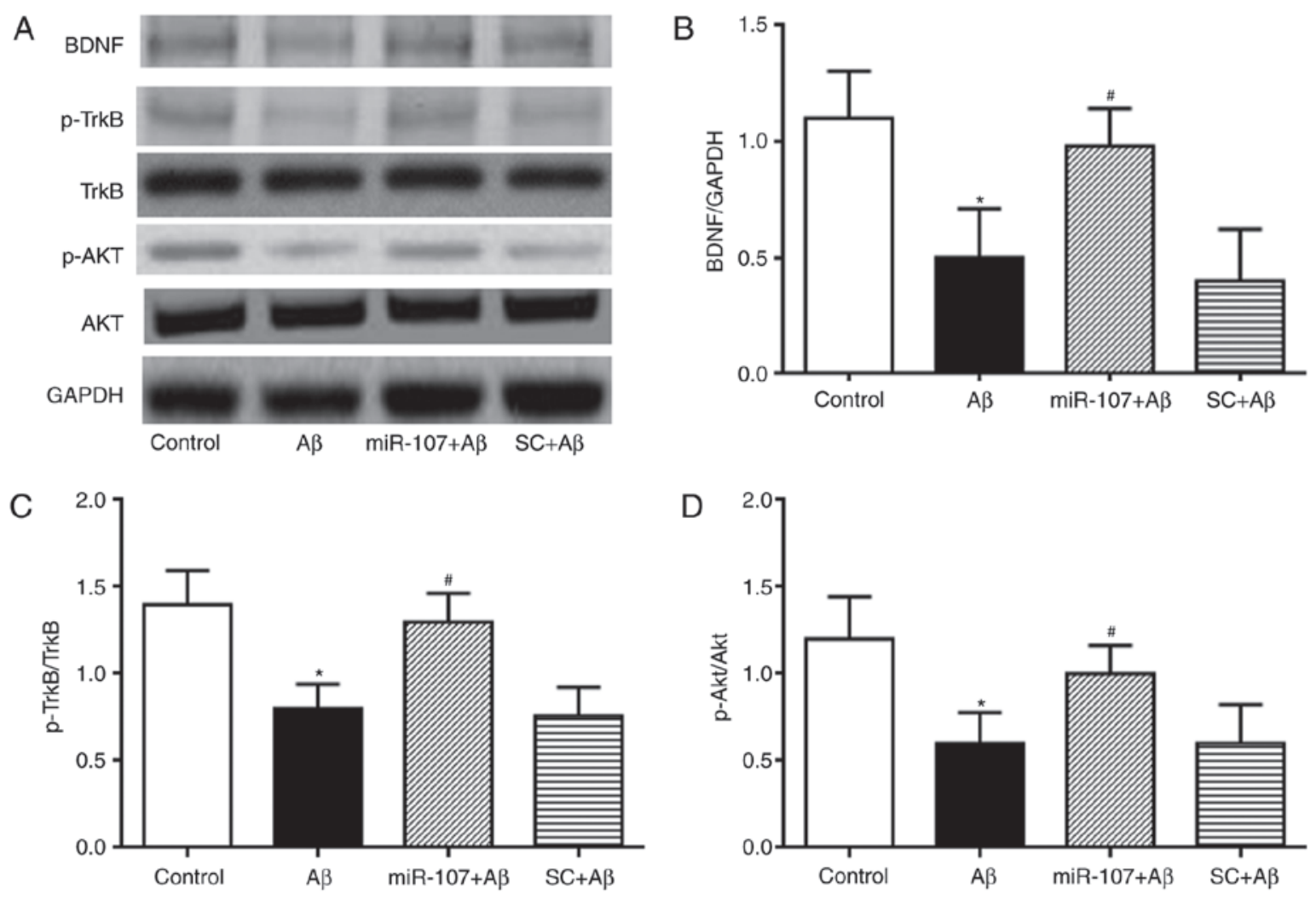

Figure 6. miR-107 mimic prevents the Aß-induced depression of BDNF-TrkB and AKT pathways. (A) Representative western blot analyses of BDNF, p-TrkB, p-AKT in different groups. (B) Quantification of BDNF expression. (C) Quantification of p-TrkB/TrkB expression. (D) Quantification of p-AKT/AKT expression. Data are presented as mean \pm standard error of the mean, as determined by one-way analysis of variance. $\mathrm{n}=12$. ${ }^{*} \mathrm{P}<0.05$ vs. control; ${ }^{~} \mathrm{P}<0.05$ vs. $\mathrm{SC}+\mathrm{A} \beta$ group. SC, scramble control; BDNF, Brain-derived neurotrophic factor; A $\beta$, amyloid $\beta$; $\mathrm{p}$-, phosphorylated; TrkB, tropomyosin receptor kinase; AKT, protein kinase B.

the CA1 area. Significant cell loss in the CA1 region following $\mathrm{A} \beta$ injection was observed; the miR-107 mimic attenuated the cell loss caused by A $\beta$ injection. Apoptosis is defined as programmed cell death and is responsible for the majority of cell death that occurs in neurodegenerative diseases (41). A $\beta$ treatment induces apoptosis in hippocampal neurons, most likely via suppression of the AKT signaling pathway $(42,43)$. The AKT pathway is an important cell survival pathway (44); therefore elimination of $\mathrm{p}$-AKT also induces the loss of pyramidal neurons following $A \beta$ injection. Although the exact 
mechanisms of action that contribute to neuronal loss were not elucidated in the present study, the reduction of BDNF-TrkB and AKT activity may contribute to cell loss. The results also indicated that $A \beta$ injection reduced the input-output of basal synaptic transmission. The loss of pyramidal neurons was consistent with the electrophysiological results.

It has been demonstrated that miR-107 directly downregulates Dicer-1, a gene that encodes an enzyme essential for processing miRNA precursors (45). This results in the inhibition of vascular endothelial growth factor translation and a decrease in its expression, leading to angiogenesis following stroke (45). Novel bioinformatics predictions, in situ hybridization experiments and biochemical validations indicate that miR-107 may be involved in the progression of AD by increasing $\beta$-secretase (18). Although the present study contained no direct evidence indicating that the miR-107 mimic ameliorates spatial memory in the AD model via the BDNF-TrkB pathway, the results indicate that BDNF expression is downregulated in AD and that the miR-107 mimic attenuates the reduction in BDNF expression induced by $\mathrm{A} \beta$ administration. Furthermore, it has been reported that miR-107 may regulate BDNF expression (46). The phosphorylation of TrkB exhibited a similar trend to BDNF expression; the BDNF-TrkB pathway is known to regulate neuronal function, most likely by modulating AKT phosphorylation (47). The present study demonstrated that AKT phosphorylation was decreased in the AD model, but was reversed by treatment with miR-107 mimic. The reductions in AKT phosphorylation and suppression of the BDNF-TrkB pathway may account for the impairment of hippocampal LTP and cell loss observed in $\mathrm{AD}$.

In conclusion, the results of the present study indicate that miR-107 levels are reduced in mice with AD phenotypes and that treatment with an miR-107 mimic increases miR-107 expression and ameliorates some of the AD phenotypes. Additionally, it was identified that the BDNF-TrkB signaling pathway may be responsible for the effects of the miR-107 mimic on $A \beta$-induced neurotoxicity. miR-107 may therefore serve as a candidate therapeutic target for the treatment of AD.

\section{References}

1. Selkoe DJ and Hardy J: The amyloid hypothesis of Alzheimer's disease at 25 years. EMBO Mol Med 8: 595-608, 2016.

2. Gong NJ, Chan CC, Leung LM, Wong CS, Dibb R and Liu C: Differential microstructural and morphological abnormalities in mild cognitive impairment and Alzheimer's disease: Evidence from cortical and deep gray matter. Hum Brain Map 38: 2495-2508, 2017.

3. Luo J, Wärmländer SK, Gräslund A and Abrahams JP: Cross-interactions between the Alzheimer disease amyloid-beta peptide and other amyloid proteins. A FURTHER ASPECT OF THE AMYLOID CASCADE HYPOTHESIS. J Biol Chem 292: 2046, 2017.

4. Hong X, Liu J, Zhu G, Zhuang Y, Suo H, Wang P, Huang D, $\mathrm{Xu}$ J, Huang Y, Yu M, et al: Parkin overexpression ameliorates hippocampal long-term potentiation and beta-amyloid load in an Alzheimer's disease mouse model. Hum Mol Genet 23: 1056-1072, 2014

5. Li F, Han G and Wu K: Tanshinone IIA alleviates the AD phenotypes in APP and PS1 transgenic mice. BioMed Res Int 2016: 7631801, 2016

6. Wang P, Wu Q, Wu W, Li H, Guo Y, Yu P, Gao G, Shi Z, Zhao B and Chang YZ: Mitochondrial ferritin deletion exacerbates $\beta$-amyloid-induced neurotoxicity in mice. Oxid Med Cell Longev 2017: 1020357, 2017.
7. Zhu J, Liao S, Zhou L and Wan L: Tanshinone IIA attenuates A $325-35$-induced spatial memory impairment via upregulating receptors for activated $\mathrm{C}$ kinase1 and inhibiting autophagy in hippocampus. J Pharm Pharmacol 69: 191-201, 2017.

8. Quinlan S, Kenny A, Medina M,Engel T and Jimenez-Mateos EM: MicroRNAs in Neurodegenerative Diseases. Int Rev Cell Mol Biol 334: 309-343, 2017.

9. Rupaimoole R and Slack FJ: MicroRNA therapeutics: Towards a new era for the management of cancer and other diseases. Nat Rev Drug Discov 16: 203-222, 2017.

10. Reddy KB: MicroRNA (miRNA) in cancer. Cancer Cell Int 15: 38, 2015.

11. Hayes J, Peruzzi PP and Lawler S: MicroRNAs in cancer: Biomarkers, functions and therapy. Trends Mol Med 20: 460-469, 2014.

12. Recasens A, Perier C and Sue CM: Role of microRNAs in the regulation of $\alpha$-Synuclein expression: A systematic review. Front Mol Neurosci 9: 128, 2016.

13. Molasy M, Walczak A, Szaflik J, Szaflik JP and Majsterek I: MicroRNAs in glaucoma and neurodegenerative diseases. J Hum Genet 62: 105-112, 2017.

14. Impey S, Davare M, Lesiak A, Fortin D, Ando H, Varlamova O, Obrietan K, Soderling TR, Goodman RH and Wayman GA: An activity-induced microRNA controls dendritic spine formation by regulating Rac1-PAK signaling. Mol Cell Neurosci 43: $146-156,2010$.

15. Nagaraj S, Laskowska-Kaszub K, Dębski KJ, Wojsiat J, Dąbrowski M, Gabryelewicz T, Kuźnicki J and Wojda U: Profile of 6 microRNA in blood plasma distinguish early stage Alzheimer's disease patients from non-demented subjects Oncotarget 8: 16122-16143, 2017

16. Reddy PH, Tonk S, Kumar S, Vijayan M, Kandimalla R, Kuruva CS and Reddy AP: A critical evaluation of neuroprotective and neurodegenerative MicroRNAs in Alzheimer's disease. Biochem Biophys Res Commun 483: 1156-1165, 2017.

17. Nelson PT and Wang WX: MiR-107 is reduced in Alzheimer's disease brain neocortex: Validation study. J Alzheimer's Dis 21: 75-79, 2010.

18. Wang WX, Rajeev BW, Stromberg AJ, Ren N, Tang G, Huang Q, Rigoutsos I and Nelson PT: The expression of microRNA miR-107 decreases early in Alzheimer's disease and may accelerate disease progression through regulation of beta-site amyloid precursor protein-cleaving enzyme 1. J Neurosci 28 : 1213-1223, 2008.

19. Jiao Y, Kong L, Yao Y, Li S, Tao Z, Yan Y and Yang J: Osthole decreases beta amyloid levels through up-regulation of miR-107 in Alzheimer's disease. Neuropharmacology 108: 332-344, 2016.

20. Kim TI, Lee YK, Park SG, Choi IS, Ban JO, Park HK, Nam SY, Yun YW, Han SB, Oh KW and Hong JT: 1-Theanine, an amino acid in green tea, attenuates beta-amyloid-induced cognitive dysfunction and neurotoxicity: Reduction in oxidative damage and inactivation of ERK/p38 kinase and NF-kappaB pathways. Free Radic Biol Med 47: 1601-1610, 2009.

21. Li J, Chen H, Wu S, Cheng Y, Li Q, Wang J and Zhu G: MPP+ inhibits mGluR1/5-mediated long-term depression in mouse hippocampus by calpain activation. Eur J Pharmacol 795: 22-27, 2017.

22. Livak KJ and Schmittgen TD: Analysis of relative gene expression data using real-time quantitative PCR and the 2(-Delta Delta C(T)) method. Methods 25: 402-408, 2001.

23. Yang ZB, Zhang Z, Li TB, Lou Z, Li SY, Yang H, Yang J, Luo XJ and Peng J: Up-regulation of brain-enriched miR-107 promotes excitatory neurotoxicity through down-regulation of glutamate transporter-1 expression following ischaemic stroke. Clin Sci (Lond) 127: 679-689, 2014.

24. Wang WX, Wilfred BR, Madathil SK, Tang G, Hu Y, Dimayuga J, Stromberg AJ, Huang Q, Saatman KE and Nelson PT: miR-107 regulates granulin/progranulin with implications for traumatic brain injury and neurodegenerative disease. Am J Pathol 177: 334-345, 2010

25. Chang RK, Li X, Mu N, Hrydziuszko O, Garcia-Majano B, Larsson $\mathrm{C}$ and Lui WO: MicroRNA expression profiles in nonepithelial ovarian tumors. Int J Oncol 52: 55-66, 2017.

26. Cao K, Li J, Chen J, Qian L, Wang A, Chen X, Xiong W, Tang J, Tang S, Chen Y, et al: microRNA-33a-5p increases radiosensitivity by inhibiting glycolysis in melanoma. Oncotarget 8: 83660-83672, 2017.

27. Müller M, Kuiperij HB, Claassen JA, Küsters B and Verbeek MM: MicroRNAs in Alzheimer's disease: Differential expression in hippocampus and cell-free cerebrospinal fluid. Neurobiol Aging 35: 152-158, 2014. 
28. Liu W, Cai H, Lin M, Zhu L, Gao L, Zhong R, Bi S, Xue Y and Shang X: MicroRNA-107 prevents amyloid-beta induced blood-brain barrier disruption and endothelial cell dysfunction by targeting Endophilin-1. Exp Cell Res 343: 248-257, 2016.

29. Yao J, Hennessey T, Flynt A, Lai E, Beal MF and Lin MT: MicroRNA-related cofilin abnormality in Alzheimer's disease. PLoS One 5: e15546, 2010.

30. Li JJ, Dolios G, Wang R and Liao FF: Soluble beta-amyloid peptides, but not insoluble fibrils, have specific effect on neuronal microRNA expression. PLoS One 9: e90770, 2014.

31. Shrestha BR, Vitolo OV, Joshi P, Lordkipanidze T, Shelanski M and Dunaevsky A: Amyloid beta peptide adversely affects spine number and motility in hippocampal neurons. Mol Cell Neurosci 33: 274-282, 2006.

32. Huang YF, Yang CH, Huang CC and Hsu KS: Vascular endothelial growth factor-dependent spinogenesis underlies antidepressant-like effects of enriched environment. J Biol Chem 287: 40938-40955, 2012.

33. Cooke SF and Bliss TV: Long-term potentiation and cognitive drug discovery. Curr Opin Investig Drugs 6: 25-34, 2005.

34. Bliss TV, Collingridge GL and Morris RG: Introduction. Long-term potentiation and structure of the issue. Philos Trans R Soc Lond B, Biol Sci 358: 607-611, 2003.

35. Zhu G, Liu Y, Wang Y, Bi X and Baudry M: Different patterns of electrical activity lead to long-term potentiation by activating different intracellular pathways. J Neurosci 35: 621-633, 2015.

36. Borba EM, Duarte JA, Bristot G, Scotton E, Camozzato AL and Chaves ML: Brain-derived neurotrophic factor serum levels and hippocampal volume in mild cognitive impairment and dementia due to Alzheimer disease. Dement Geriatr Cogn Dis Extra 6: $559-567,2016$.

37. Nie J, Tian Y, Zhang Y, Lu YL, Li LS and Shi JS: Dendrobium alkaloids prevent Abeta25-35-induced neuronal and synaptic loss via promoting neurotrophic factors expression in mice. PeerJ 4 e2739, 2016

38. Braak $\mathrm{H}$ and Braak E: Ratio of pyramidal cells versus non-pyramidal cells in the human frontal isocortex and changes in ratio with ageing and Alzheimer's disease. Prog Brain Res 70: $185-212,1986$
39. Ditter SM and Mirra SS: Neuropathologic and clinical features of Parkinson's disease in Alzheimer's disease patients. Neurology 37: 754-760, 1987.

40. Maingret V, Barthet G, Deforges S, Jiang N, Mulle C and Amédée T: PGE2-EP3 signaling pathway impairs hippocampal presynaptic long-term plasticity in a mouse model of Alzheimer's disease. Neurobiology Aging 50: 13-24, 2017.

41. Saleem S and Biswas SC: Tribbles Pseudokinase 3 induces both apoptosis and autophagy in amyloid- $\beta$-induced neuronal death. J Biol Chem 292: 2571-2585, 2017.

42. Xiao H, Zhang Q, Peng Y, Tang G, Liao Y, Zhuang X, Ye WC, Wang Y and Shi L: 7-(4-Hydroxy-3-methoxyphenyl)-1-phenyl-4Ehepten-3-one alleviates Abeta1-42 induced cytotoxicity through PI3K-mTOR pathways. Biochem Biophys Res Commun 484: 365-371, 2017.

43. Chen L, Ou S, Zhou L, Tang H, Xu J and Guo K: Formononetin attenuates A $\beta 25-35$-induced cytotoxicity in HT22 cells via PI3K/Akt signaling and non-amyloidogenic cleavage of APP. Neurosci Lett 639: 36-42, 2017.

44. Zhu G, Wang X, Wu S and Li Q: Involvement of activation of $\mathrm{PI} 3 \mathrm{~K} / \mathrm{Akt}$ pathway in the protective effects of puerarin against MPP+-induced human neuroblastoma SH-SY5Y cell death. Neurochem Int 60: 400-408, 2012.

45. Li Y, Mao L, Gao Y, Baral S, Zhou Y and Hu B: MicroRNA-107 contributes to post-stroke angiogenesis by targeting Dicer-1. Sci Rep 5: 13316, 2015.

46. Xia H, Li Y and Lv X: MicroRNA-107 inhibits tumor growth and metastasis by targeting the BDNF-mediated PI3K/AKT pathway in human non-small lung cancer. Int $\mathrm{J}$ Oncol 49: 1325-1333, 2016.

47. Qian Q, Liu Q, Zhou D, Pan H, Liu Z, He F, Ji S, Wang D, Bao W, Liu X, et al: Brain-specific ablation of Efr3a promotes adult hippocampal neurogenesis via the brain-derived neurotrophic factor pathway. FASEB J 31: 2104-2113, 2017. 